\title{
A Complete Procedure for Crop Phenology Estimation With PolSAR Data Based on the Complex Wishart Classifier
}

\author{
Lucio Mascolo, Member, IEEE, Juan M. Lopez-Sanchez, Senior Member, IEEE, \\ Fernando Vicente-Guijalba, Student Member, IEEE, Ferdinando Nunziata, Senior Member, IEEE, \\ Maurizio Migliaccio, Senior Member, IEEE, and Giuseppe Mazzarella, Senior Member, IEEE
}

\begin{abstract}
A new methodology to estimate the growth stages of agricultural crops using the time series of polarimetric synthetic aperture radar (PolSAR) images is proposed. The methodology is based on the complex Wishart classifier and both phenological intervals and training areas are identified measuring the distances among polarimetric covariance matrices obtained from the time series of PolSAR data. Consequently, the computation of PolSAR features, which is the main step of state-of-the-art methods, is no longer needed, and the proposed approach can be applied in the same way to any crop type. Experiments undertaken on a dense time series of fully polarimetric C-band RADARSAT-2 images, collected at incidence angles ranging from $23^{\circ}$ to $39^{\circ}$, in ascending/descending orbit passes, demonstrate that the proposed methodology can be successfully applied to retrieve the phenological stages of four different crop types. In addition, the effect of combining beams corresponding to different sensor's configurations has been evaluated, showing that it affects the retrieval accuracies. Validation with ground data shows the following: overall accuracy is between $54 \%$ and $86 \%$; producer's accuracy (PA) and user's accuracy (UA) range between $21 \%$ and $100 \%$ and between $33 \%$ and $100 \%$, respectively.
\end{abstract}

Index Terms-Agriculture, classification, phenology, polarimetry, synthetic aperture radar (SAR).

\section{INTRODUCTION}

C ROP phenology denotes the continuous evolution of agricultural crops along the cultivation cycle, and it is generally subdivided into primary and secondary stages [1], [2].

Tracking phenological stages of crops is a matter of great importance both for farmers, to trigger and plan farming activi-

Manuscript received August 12, 2015; revised December 16, 2015, May 2, 2016, and June 8, 2016; accepted June 22, 2016. This work was supported in part by the Spanish Ministry of Economy and Competitiveness (MINECO) and EU FEDER under Projects TEC2011-28201-C02-02 and TIN2014-55413C2-2-P.

L. Mascolo, F. Nunziata, and M. Migliaccio are with the Dipartimento di Ingegneria, Università degli Studi di Napoli Parthenope, 80143 Naples, Italy (e-mail: lucio.mascolo@uniparthenope.it; ferdinando.nunziata@ uniparthenope.it; maurizio.migliaccio@ uniparthenope.it).

J. M. Lopez-Sanchez and F. Vicente-Guijalba are with the Institute of Computing Research (IUII), University of Alicante, 03690 Alicante, Spain (e-mail: juanma.lopez@ua.es; fernando.vicente@ua.es).

G. Mazzarella is with the Dipartimento di Ingegneria Elettrica ed Elettronica, Università degli Studi di Cagliari, 09124 Cagliari, Italy (e-mail: mazzarella@ diee.unica.it)

Color versions of one or more of the figures in this paper are available online at http://ieeexplore.ieee.org.

Digital Object Identifier 10.1109/TGRS.2016.2585744 ties, and for those national/international authorities focused on scheduling yield calendars for market predictions, regulation of price, etc. Farming practices aimed at optimizing the crop yield, such as fertilization, irrigation, and fungicide applications, rely on timely information about the crop status. For instance, in the case of cereals, nitrogen fertilizers are mostly applied during the stem elongation stage [3], and therefore, this stage has to be correctly identified. An important aspect concerns also pest infestations and plant diseases, whose effects on crops depend primarily on the growth stages at which attacks and infections occur [4]. For instance, the final yield of wheat is strongly affected by wheat midges only if they attack plants during the flowering stage [4], while the barley yellow dwarf virus has a great influence on cereal yield when plants are infected between the early emergence and the booting stages [4]. Therefore, in order to minimize the final yield losses, farmers need to detect these stages to prevent such pests and infections.

Crop growth stages are conventionally detected by groundbased monitoring activities. The latter, although providing accurate stages identification, are both not cost-effective and very difficult to be routinely implemented, especially for extensive fields (e.g., the stem elongation stage in cereals is commonly identified by cutting longitudinally the stems and analyzing their extension [3]). Within this framework, the use of remote sensing is essential: it allows a synoptic and continuous coverage of wide agricultural areas. In particular, synthetic aperture radar (SAR) is a key tool since it ensures both day and night almost all weather observations at fine spatial resolution. With this respect, the sensitivity of polarization of electromagnetic waves to the geometrical (size, shape, orientation, etc.) and dielectric properties (biomass, water content, etc.) of the plants, which vary as a function of crop type, growth stage, and crop conditions, aroused a great interest in exploiting polarimetric SAR (PolSAR) measurements for monitoring the growth stages of crops. Spaceborne coherent PolSAR sensors, such as RADARSAT-2 (C-band), TerraSAR-X (X-band), and the most recently launched Sentinel-1 (S1) operating at C-band, provide a revisit time (24 days for RADARSAT-2, 11 days for TerraSAR-X, 12 days for S1-A, and 6 days when combining S1-A and S1-B) which can be further reduced by combining different beams and ascending/descending orbits (especially in the case of RADARSAT-2). This represents a key advantage for this application since a dense time sampling throughout the growing season is necessary from the application point of 
view to provide updated information with enough refresh rate. However, combining different beams, i.e., acquisitions with different sensor configurations, may complicate the analysis and exploitation of the data, as it will be pointed out later in this paper.

Recent studies [5]-[20] have shown the potential of PolSAR measurements to monitor the growth stages of agricultural crops in a robust and efficient way. PolSAR-based approaches have been proposed for crop phenology estimation [7]-[20], where phenology retrieval is treated as a classification problem: crop growth stages are regarded as classes, and hence, they are identified by means of classification algorithms. The latter can be statical or dynamical [15]. In statical approaches, the classification is applied to each PolSAR image, without accounting for the time variable. As a consequence, for instance, the phenology of a parcel may be classified as late ripening at time $t_{n}$ and then as early germination at time $t_{n+1}$. This issue is solved by dynamical approaches, i.e., the ones proposed in [14]-[16], where crop development is modeled as a dynamical process and phenology estimation is framed in a dynamical system context. In the literature, statical approaches have been proposed in [7]-[13] and [17], and they basically consist of two steps. In the first one, the behavior of PolSAR features is physically interpreted in terms of the phenological stages of the crop under study. Such an analysis allows selecting a reduced set of features, i.e., the ones that result in the less ambiguous identification of the phenological intervals to be classified. In the second step, hierarchical trees and/or simple decision planes are defined by thresholding manually the evolution of the selected features and then used for the final phenology classification. Those approaches present some drawbacks. First, a wide number of PolSAR features (backscattering coefficients at different polarization bases, correlations and phase differences, decomposition outputs, etc.) must be analyzed to choose the features that best perform for classification purposes. More importantly, for a given crop type, the methodology is tuned for a specific test area, and therefore, this limits its operational use. An additional drawback of these approaches, recently discussed in [17] and [18], is the difficulty to identify and define phenological intervals to be classified. Some transitions between phenological stages are not well defined in the space defined by the selected features, which, in turn, will lead to poor performance of the estimation (classification) algorithm.

In this paper, a novel statical approach is proposed to overcome these drawbacks. It is based on a robust strategy which, in turn, relies on the complex Wishart classifier, a well-known supervised classification method for PolSAR imagery [21]. The proposed methodology exploits distances among covariance matrices derived from time series of PolSAR images to identify both the phenological intervals to be estimated and, for each interval, the training sets. Finally, these intervals are classified by the complex Wishart classifier.

Therefore, in contrast to state-of-the-art studies, the proposed methodology does not rely on specific PolSAR features, but it is only based on the covariance matrices. This is of great relevance since the whole polarimetric information contained in these basic polarimetric matrices is exploited. As a con- sequence, the computation and analysis of sets of PolSAR features, as well as their physical interpretation, are no longer needed and, contrarily to rule-based algorithms that need to be tuned according to the crop type, in this case the same classification algorithm, i.e., the complex Wishart classifier, are used for all crops. A potential advantage of approaches based on features, and not only on the covariance matrices and Wishart distances, is the exploitation of other types of information, like texture, which are not considered in this methodology. In addition, the proposed method encompasses the distance between phenological classes, so some of the challenges in feature-based works (e.g., one-to-many relation between temporal behavior of crops and backscattering) are also valid for the proposed scheme.

The proposed approach is tested over different crop types that characterize an agricultural test site located near Barrax, Spain, for which a dense time series of full-polarimetric C-band RADARSAT-2 SAR images is available. Such a times series is achieved by combining seven different beams (i.e., different orbit passes and different incidence angles) acquired in the framework of the European Space Agency (ESA) funded Agricultural bio/geophysical retrieval from frequent repeat pass SAR and optical imaging (AgriSAR) campaign, conducted in that area in 2009, which provided ground information about the crop phenological stages. Note that the same SAR and ground data have been used in [6], [11], and [12] for phenology retrieval and in [22] to analyze the sensitivity of the backscattering coefficients to crop growth stages and soil conditions. In this paper, four different crop types are analyzed: oat, barley, wheat, and corn. Results show that the methodology successfully estimates the phenological stages of the four crop types.

This paper is organized as follows. The basic theory concerning the complex Wishart classifier is summarized in Section II. In Section III, the proposed approach is detailed. A description of the test site, ground truth, and SAR data is provided in Section IV. The obtained results are shown and discussed in Section V, and finally, in Section VI, conclusions are drawn.

\section{COMPLEX Wishart ClASSIFIER}

PolSAR measurements can be expressed in terms of the multilooked polarimetric covariance matrix $\mathbf{C}$ which, assuming reciprocity, is a $3 \times 3$ Hermitian and semidefinite positive matrix [23]

$$
\begin{aligned}
\mathbf{C} & =\frac{1}{L} \sum_{l=1}^{L} \mathbf{k}_{(l)} \mathbf{k}_{(l)}^{\dagger} \\
& =\left[\begin{array}{ccc}
\left\langle\left|S_{\mathrm{hh}}\right|^{2}\right\rangle & \sqrt{2}\left\langle S_{\mathrm{hh}} S_{\mathrm{hv}}^{*}\right\rangle & \left\langle S_{\mathrm{hh}} S_{\mathrm{vv}}^{*}\right\rangle \\
\sqrt{2}\left\langle S_{\mathrm{hv}} S_{\mathrm{hh}}^{*}\right\rangle & 2\left\langle\left|S_{\mathrm{hv}}\right|^{2}\right\rangle & \sqrt{2}\left\langle S_{\mathrm{hv}} S_{\mathrm{vv}}^{*}\right\rangle \\
\left\langle S_{\mathrm{vv}} S_{\mathrm{hh}}^{*}\right\rangle & \sqrt{2}\left\langle S_{\mathrm{vv}} S_{\mathrm{hv}}^{*}\right\rangle & \left\langle\left|S_{\mathrm{vv}}\right|^{2}\right\rangle
\end{array}\right]
\end{aligned}
$$

where $L$ is the number of looks, $\mathbf{k}=\left[S_{\mathrm{hh}}, \sqrt{2} S_{\mathrm{hv}}, S_{\mathrm{vv}}\right]$ is the one-look Lexicographic target vector expressed in the horizontal $(h) / \operatorname{vertical}(v)$ basis, $S_{\mathrm{xy}}$ is the complex scattering coefficient with $\{x, y\}=\{h, v\}$, and $\langle\cdot\rangle$ and ${ }^{\dagger}$ denote the spatial averaging and the complex conjugate transpose, respectively. 
Under the hypothesis of fully developed speckle [23], it can be shown that $\mathbf{C}$ follows a complex Wishart distribution [24]

$$
p_{\mathbf{C}}(\mathbf{C})=\frac{n^{3 L}|\mathbf{C}|^{L-3} \exp \left[-n \operatorname{Tr}\left(\mathbf{C}_{E}^{-1} \mathbf{C}\right)\right]}{K(n)\left|\mathbf{C}_{E}\right|^{L}}
$$

where $\mathbf{C}_{E}=E[\mathbf{C}$, with $E[\cdot]$ denoting the ensemble average, and $K(L)=\pi^{3}[\Gamma(L) \Gamma(L-1) \Gamma(L-2)]$, with $\Gamma(\cdot)$ and $\operatorname{Tr}(\cdot)$ denoting the gamma function and the matrix trace, respectively.

PolSAR data are largely exploited for land cover classification purposes. Among the several classification methods proposed, purely statistics approaches, e.g., [21], and statistics/model-based approaches, e.g., [25], are adopted. In this paper, the complex Wishart classifier [21] is exploited for crop phenology estimation. This is a supervised classification approach based on the Bayesian maximum likelihood classification criterion, which exploits the Wishart distribution of $\mathbf{C}$ for classes discrimination. By assuming an equal a priori probability for all of the classes, the distance between a given pixel and the $m$ th class $\omega_{m}$ is derived from (2) as

$$
d\left(\mathbf{C}, \mathbf{C}_{E_{m}}\right)=\ln \left|\hat{\mathbf{C}}_{E_{m}}\right|+\operatorname{Tr}\left(\hat{\mathbf{C}}_{E_{m}}^{-1} \mathbf{C}\right)
$$

where $\mathbf{C}_{E_{m}}=E\left[\mathbf{C} \mid \mathbf{C} \in \omega_{m}\right]$ is the average covariance matrix of all of the pixels belonging to $\omega_{m}$.

The supervised Wishart classification is summarized as follows: first, training areas have to be selected; then, $\mathbf{C}_{E_{m}}$ is evaluated by considering pixels within the selected training areas; finally, classes discrimination is performed by assigning a given pixel to the class $\omega_{m}$, based on the lowest distance criterion

$$
d\left(\mathbf{C}, \mathbf{C}_{E_{m}}\right) \leq d\left(\mathbf{C}, \mathbf{C}_{E_{u}}\right), \quad \forall \omega_{u} \neq \omega_{m}
$$

with $\mathbf{C}_{E_{u}}$ being the average covariance matrix of the pixels belonging to class $\omega_{u}$.

\section{Methodology}

The methodology proposed to exploit the complex Wishart classifier for crop phenology estimation is based on the covariance matrices derived from the time series of PolSAR images collected on the study area. Given $N$ PolSAR images, available over an agricultural region, the $N$ multilooked $3 \times 3$ covariance matrices, evaluated within the parcels of interest, are arranged in a unique matrix termed as a mosaic and hereinafter referred as $\mathbf{N}_{\mathbf{C}}$. The $n$th mosaic tile corresponds to the matrix $\mathbf{C}_{n}$ relevant to the $n$th datum of the time series. This simple mosaicking operation allows treating parcel phenological stages as different classes in a single image, i.e., $\mathbf{N}_{\mathbf{C}}$. Hence, the complex Wishart classifier is here used to discriminate these classes within $\mathbf{N}_{\mathbf{C}}$.

Once $\mathbf{N}_{\mathbf{C}}$ is built, the proposed methodology foresees two main steps: 1) the identification step, which consists of identifying the phenological intervals to be estimated, and 2) the selection step, which consists of selecting training areas for each interval (a training area corresponds to the whole parcel, and hence, it is referred to as the training tile). These two steps are based on the symmetric revised Wishart distance (SRWD) $d_{\text {SRW }}$ [26], evaluated among mosaic tiles. The pairwise $d_{\text {SRW }}$

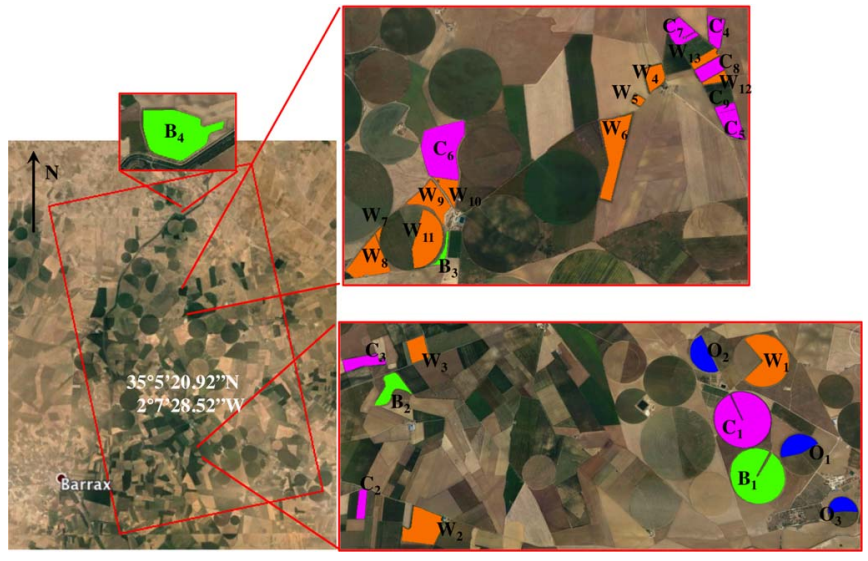

Fig. 1. Google Earth photographs of the parcels analyzed in this study.

between the covariance matrix of the $i$ th tile $\mathbf{C}_{i}$ and the covariance matrix of the $j$ th tile $\mathbf{C}_{j}$ is defined as

$$
d_{\mathrm{SRW}}\left(\mathbf{C}_{i}, \mathbf{C}_{j}\right)=\frac{1}{2} \operatorname{Tr}\left(\mathbf{C}_{i} \mathbf{C}_{j}^{-1}+\mathbf{C}_{j} \mathbf{C}_{i}^{-1}\right)-3
$$

which satisfies the conditions: $d_{\mathrm{SRW}}\left(\mathbf{C}_{i}, \mathbf{C}_{j}\right)=d_{\mathrm{SRW}}\left(\mathbf{C}_{j}, \mathbf{C}_{i}\right)$, and $d_{\mathrm{SRW}}\left(\mathbf{C}_{i}, \mathbf{C}_{i}\right)=0$. Both the identification and the selection steps will be detailed in Section $\mathrm{V}$.

\section{Test Site, Ground Measurements, AND SAR DATA}

The test site is located near Barrax (Spain), which belongs to the Albacete province and is on the La Mancha plateau at $700 \mathrm{~m}$ above sea level.

Due to the presence of many agricultural fields, the Barrax area has been often used as a test site for remote sensing experiments, e.g., [22] and [27]. The proposed methodology is tested over 29 agricultural fields monitored during the AgriSAR 2009 field campaign between the spring and autumn seasons: 3 oat parcels, referred as " $\mathrm{O}_{1}$," " $\mathrm{O}_{2}$," and " $\mathrm{O}_{3}$ "; 4 barley parcels, referred as " $\mathrm{B}_{1}$, " " $\mathrm{B}_{2}$, ," $\mathrm{B}_{3}$," and " $\mathrm{B}_{4}$ "; 13 wheat parcels, referred as " $\mathrm{W}_{1}$, " " $\mathrm{W}_{2}$ "..." $\mathrm{W}_{13}$ "; and 9 corn parcels, referred to as " $\mathrm{C}_{1},{ }^{\prime}$ " $\mathrm{C}_{2}$ " ..." $\mathrm{C}_{9}$." These parcels are clearly visible in the Google Earth photograph shown in Fig. 1.

Ground data relevant to the analyzed crops, available from the AgriSAR 2009 field survey, are listed in Table I, and they include crop phenology, irrigation schedule and harvest date (provided only for some parcels), and row orientation (provided only for some corn parcels). Unfortunately, further information regarding soil moisture, soil roughness, row orientation, etc., is not available. Regarding the phenological stages of the parcels, ground measurements provided only rough information about the time extent (defined by start and end dates) of each recorded stage. Hence, in order to provide an agronomy-based description of the parcel phenology, we assign at the start/end dates of each growth stage a numerical code according to the $\mathrm{BBCH}$ scale (from Biologische Bundesanstalt, Bundessortenamt und CHemische Industrie) [1], which ranges from 0 to 99 . The recorded growth stages, expressed in terms of the $\mathrm{BBCH}$ scale, are also reported in Table I. Note that, regarding oat, barley, and wheat, the seedling stage should refer to the plants leaf 
TABLE I

Ground Data Available From the Agrisar 2009 Field Campaign

\begin{tabular}{|c|c|c|c|}
\hline \multicolumn{2}{|c|}{ Oat / Barley / Wheat } & \multicolumn{2}{|l|}{ Corn } \\
\hline Phenology (ground data) & BBCH scale & Phenology (ground data) & BBCH scale \\
\hline Seedling & $10-19$ & Seedling & $0-9$ \\
\hline Tillering & $20-29$ & $2 / 3$ leaves $-4 / 5$ leaves & $10-15$ \\
\hline Stem growth/booting & $30-49$ & Development & $30-59$ \\
\hline Head emergence and flowering & $50-69$ & Flowering & $60-69$ \\
\hline Kernel milk dough/kernel dough/kernel hard & $70-89$ & Kernel milk/kernel dough/ripening & $70-89$ \\
\hline Harvest date & 99 & Harvest date & 99 \\
\hline \multicolumn{4}{|c|}{ Additional information } \\
\hline $\begin{array}{l}\text { Harvest date (DoY) } \\
\text { - All oat parcels: July 23/24 (DoY 204/205) } \\
\text { - Parcel } B_{1} \text { : July 7/8 (DoY 188/189) } \\
\text { - Parcel W } W_{1} \text { : July } 16 \text { (DoY 196) } \\
\text { - Parcel } C_{1} \text { : November 17/20 (DoY 321/324) }\end{array}$ & $\begin{array}{l}\text { Irrigation schedule } \\
\text { - Parcels } \mathrm{O}_{2} \text { and } \mathrm{O}_{3} \text { : DoYs 71-195 } \\
\text { - Parcel } \mathrm{B}_{1} \text { : DoYs 70-189 } \\
\text { - Parcel } \mathrm{W}_{1} \text { : DoYs 74-196 } \\
\text { - Parcel } \mathrm{C}_{1} \text { : DoYs 133-263 }\end{array}$ & $\begin{array}{l}\text { Row orientation } \\
\text { - Parcels } \mathrm{C}_{2}, \mathrm{C}_{6}, \mathrm{C}_{7} \text { : East - West } \\
\text { - Parcels } \mathrm{C}_{3} \text { : EastNorthEast-WestSouthWest } \\
\text { - Row spacing: } 70-80 \mathrm{~cm}\end{array}$ & \\
\hline
\end{tabular}

TABLE II

CHARACTERISTICS OF THE RADARS AT-2 FQ BEAMS AND ACQUISITION SEQUENCE. "A" STANDS FOR ASCENDING AND "D" STANDS FOR DESCENDING

\begin{tabular}{c|c|c|c|c}
\hline Beam & AOI $\left(^{\circ}\right)$ & Pass & $\begin{array}{c}\text { Pixel spacing } \\
\text { [Azimuth } \times \text { Slant-range }(\mathrm{m})\end{array}$ & $\begin{array}{c}\text { ENL } \\
(9 \times 9 \text { boxcar })\end{array}$ \\
\hline FQ4 & 23 & A & $4.92 \times 4.73$ & 47.7 \\
\hline FQ6 & 25 & D & $4.69 \times 4.73$ & 45.5 \\
\hline FQ9 & 28 & A & $4.81 \times 4.73$ & 46.6 \\
\hline FQ11 & 31 & D & $5.58 \times 4.73$ & 54 \\
\hline FQ14 & 34 & A & $4.76 \times 4.73$ & 46 \\
\hline FQ16 & 36 & D & $5.15 \times 4.73$ & 50 \\
\hline FQ20 & 39 & A & $4.79 \times 4.73$ & 46.5 \\
\hline
\end{tabular}

Acquisition Sequence

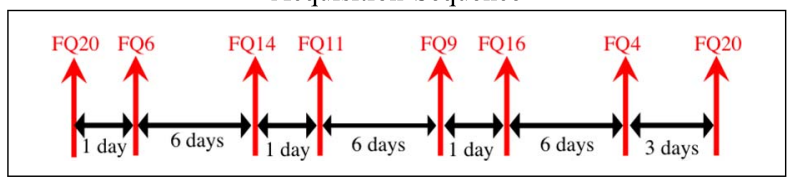

development (BBCH 10-19) [2]. Furthermore, it is important to point out that, although the booting stage (BBCH 40-49) is not recorded by ground measurements, to be consistent with the growth of these crops, the end date of the stem growth stage is coded as 49 (i.e., end of booting). Regarding corn, the seedling stage should refer to the germination stage (BBCH 0-9) since, according to the duration of the germination of corn [28], it lasts five days for all of the parcels but $\mathrm{C}_{2}$ (where it lasts ten days). Concerning the development stage, it should consist of the stem elongation and heading stages, i.e., from BBCH 30 to 59.

It must be underlined that, except for some cases, the duration of the growing cycle of the parcels belonging to the same crop type differs among parcels. In these cases, growing cycles start on different dates, and parcels develop at different rates.

The PolSAR time series consists of seven Fine-Quad-Pol (FQ) RADARSAT-2 beams, corresponding to 50 single-look complex (SLC) images, collected over the Barrax area from April 2, i.e., day of year (DoY) 92, to September 25 (DoY 268). The characteristics of these beams, collected at AOIs ranging from $23^{\circ}$ to $39^{\circ}$, are listed in Table II, where also the acquisition schedule is reported. The combination of several frames corresponding to different sensor configurations ensures a dense time sampling (Table II) with the lower and largest time gaps between acquisitions being one and six days, respectively. However, mixing ascending and ascending passes collected at different AOIs may have a significant influence on the polarimetric response of the crops [29], [30], especially when images
TABLE III

Subsets of RADARS AT-2 IMAGES UEd For EACH PARCEL

\begin{tabular}{c|c|c|c}
\hline Parcel/s & Beams coverage & AOIs $<30^{\circ}$ & All AOIs \\
\hline $\mathrm{O}_{1}-\mathrm{O}_{3}$ & All & $N=14$ & $N=33$ \\
\hline $\mathrm{B}_{1}$ & All & $N=12$ & $N=28$ \\
\hline $\mathrm{B}_{2}$ & FQ4 - FQ16 & $N=10$ & $N=21$ \\
\hline $\mathrm{B}_{3}$ & All & $N=10$ & $N=25$ \\
\hline $\mathrm{B}_{4}$ & $\mathrm{FQ} 4-\mathrm{FQ} 14$ & $N=10$ & $N=18$ \\
\hline $\mathrm{W}_{1}$ & All & $N=13$ & $N=31$ \\
\hline $\mathrm{W}_{2}-\mathrm{W}_{3}, \mathrm{~W}_{7}$ & FQ4 - FQ16 & $N=11$ & $N=23$ \\
\hline $\mathrm{W}_{4}-\mathrm{W}_{6}, \mathrm{~W}_{9}-\mathrm{W}_{13}$ & All & $N=11$ & $N=27$ \\
\hline $\mathrm{W}_{8}$ & $\mathrm{FQ} 4-\mathrm{FQ14}$ & $N=11$ & $N=19$ \\
\hline $\mathrm{C}_{1}$ & All & $N=14$ & $N=34$ \\
\hline $\mathrm{C}_{2}$ & $\mathrm{FQ4}-\mathrm{FQ16}$ & $N=17$ & $N=31$ \\
\hline $\mathrm{C}_{3}$ & $\mathrm{FQ} 4-\mathrm{FQ14}$ & $N=15$ & $N=26$ \\
\hline $\mathrm{C}_{4}, \mathrm{C}_{5}, \mathrm{C}_{7}-\mathrm{C}_{9}$ & All & $N=16$ & $N=35$ \\
\hline $\mathrm{C}_{6}$ & All & $N=17$ & $N=37$ \\
\hline
\end{tabular}

are acquired on consecutive days, e.g., beams FQ20 (ascending pass, $\mathrm{AOI} \approx 39^{\circ}$ ) and $\mathrm{FQ6}$ (descending pass, $\mathrm{AOI} \approx 25^{\circ}$ ).

For each crop type, a specific subset of the available $50 \mathrm{im}$ ages is used, which includes only those data acquired during the cultivation cycle and up to two or three days before harvesting (when the harvest date is provided). It is important to underline that the seedling stage of oat, barley, and wheat occurs during March, and it cannot be analyzed in this study (PolSAR acquisitions are available from the beginning of April). The number of images used for all of the parcels belonging to each crop type is reported in Table III. Note that, unlike oat, different subsets of images are used for parcels belonging to barley, wheat, and corn crops due to the time extent of the growing cycles and beams coverage.

Finally, data preprocessing consists basically of a few steps. In the first step, SLC images of each beam are coregistered, by choosing one image of the beam as master. In the second step, covariance matrices are estimated from every SLC image by a $9 \times 9$ sliding boxcar filter. According to the characteristics of the RADARSAT-2 FQ beams, such a window's size results in an equivalent number of looks (ENL) around 48 (see Table II), which provides reliable estimates of the $\mathbf{C}$ matrix [23]. The third step consists of geocoding all of these matrices to a common Universal Transverse of Mercator grid that is defined to have all of the geocoded products in the same reference grid, regardless of their orbit pass. For geocoding, a 90-m resolution Shuttle Radar Topography Mission digital elevation model is used. The selected pixel spacing in the geocoded images is $5 \mathrm{~m}$ in both coordinates. 


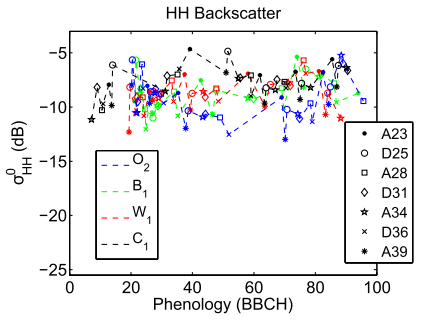

(a)

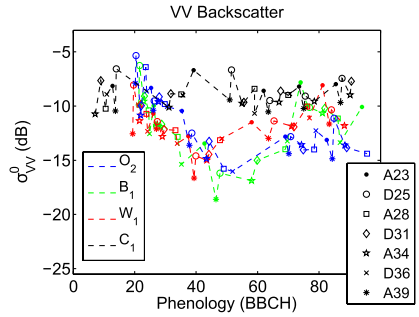

(b)

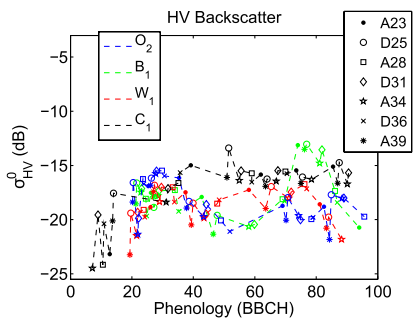

(c)

Fig. 2. Evolution of the co- and cross-polarized backscattering coefficients for parcels $\mathrm{O}_{2}, \mathrm{~B}_{1}, \mathrm{~W}_{1}$, and $\mathrm{C}_{1}$

\section{EXPERIMENTS}

In this section, experiments undertaken on the SAR data set are presented and discussed. A brief description of the behavior of the backscattering coefficients at linear polarizations (diagonal elements of $\mathbf{C}$ ), evaluated along the cultivation cycle of oat, barley, wheat, and corn parcels, is first provided in Section V-A. Then, the proposed methodology is applied to estimate the phenological stages of these parcels in Section V-B. It must be noted that, since we do not have the same number of PolSAR acquisitions for all of the parcels of the same crop type (see Table III) and the latter do not exhibit the same phenology at the same date, the backscattering coefficients, as well as the pairwise SRWDs (5) between mosaic tiles, are analyzed as a function of the $\mathrm{BBCH}$ scale associated with ground data. $\mathrm{BBCH}$ codes at the radar acquisition dates are obtained by a linear interpolation [7].

\section{A. Backscattering Coefficients at Linear Polarizations}

A complete description of the behavior of the backscattering coefficients relevant to the analyzed crop types is provided in [22], where the same data set is used. However, for the sake of completeness, the evolution of the $\mathrm{HH}, \mathrm{VV}$, and $\mathrm{HV}$ backscattering for parcels $\mathrm{O}_{2}, \mathrm{~B}_{1}, \mathrm{~W}_{1}$, and $\mathrm{C}_{1}$ is here reviewed (see Fig. 2). In these plots, the mean values of the three intensities, evaluated within each parcel, are shown, and each beam is denoted by the orbit pass ("A" stands for ascending, and " $\mathrm{D}$ " stands for descending) and the average AOI.

In the case of small-grain cereals, i.e., oat, barley, and wheat, the radar response is dominated by the scattering from the soil attenuated by plants throughout the growing season [31]-[33]. Accordingly, the HV intensity is mainly below $-15 \mathrm{~dB}$, which is in agreement with the results reported in [34] for cereal crops analyzed in different test sites. Regarding the backscattering at copolar channels, the different behavior of the $\mathrm{HH}$ and VV intensities before heading (BBCH 20-50) is due to the vertical orientation of the stems, which significantly attenuates the VV intensity with respect to the $\mathrm{HH}$ one. Note that the largest VV attenuation occurs at heading (BBCH 50) for oat and barley and at the start of booting (BBCH 40) for wheat. Then, the wheat parcel exhibits an increase of the VV intensity, which could be attributed to the development of the heads within the sheath of the flag leaves. As the parcels approach ripening $(\mathrm{BBCH}$ 80), backscattering intensities increase due to the increasing moisture content in the heads [35], [36]. Note that the VV intensity exhibits the largest increase due to the progressive drying of the stems, which reduces the attenuation at the $\mathrm{VV}$ channel. Finally, at senescence (BBCH 90-100), an overall decrease is experienced for these three parcels.

Regarding corn, the scattering from slightly rough/rougher surface is the dominant scattering mechanism when the soil is mostly bare, i.e., at $\mathrm{BBCH}<15$. Accordingly, the VV intensity is slightly larger than the $\mathrm{HH}$ one, with $\mathrm{HV}$ being below $-20 \mathrm{~dB}$. Then, up to $\mathrm{BBCH} 40$, the emerging (large and randomly oriented) corn leaves lead to similar increasing copolarized intensities and to a sharp increase of the cross-polarized one. Finally, according to [35], the high plant biomass leads to a saturation of the backscattering of all of the intensities from BBCH 50 onward.

The analysis of the backscattering intensities demonstrates that the latter carry on valuable information on the phenological stages of the four crop types. However, this information is contaminated by disturbing parameters related both to the system configuration (e.g., incidence angle) and scene properties (e.g., soil moisture and row orientation). For instance, in the case of small-grain cereals, the backscattering analysis shows that, before heading, the attenuation of soil backscattering caused by the emerging tillers (BBCH 20-30) and then by the almost vertical stems (BBCH 30-40) is more pronounced at larger AOIs. This phenomenon can be clearly observed looking at the VV backscattering of the barley parcel around BBCH 45. One can note that the backscattering related to beam A23 is $\sim 5 / 6 \mathrm{~dB}$ larger than the one related to beam A39. Scene properties, e.g., soil moisture and row orientation, can fairly explain the unexpected behavior of the backscattering intensities. For instance, the sharp increase of all of the intensities observed around BBCH 24 for parcel $\mathrm{O}_{2}$ (beam A28) is likely caused by the irrigation of the parcel $(6.65 \mathrm{~mm}$ of water), which occurred on the acquisition day. Moreover, for parcel $\mathrm{B}_{1}$, irrigation has a strong impact also in the milking stage (BBCH 70-80), which, for this parcel, results in VV and HV backscattering significantly larger than the oat and wheat ones. In this phenological range, parcel $B_{1}$ received $\sim 111 \mathrm{~mm}$ of water from irrigation, while parcels $\mathrm{W}_{1}$ and $\mathrm{O}_{2}$ were irrigated with $\sim 58$ and $\sim 89 \mathrm{~mm}$, respectively. Hence, at these stages, the backscattering of parcel $B_{1}$ is likely affected by this irrigation. In the case of corn, the large variation of the HV backscattering at earlier stages is likely due to different soil moisture levels related to the irrigation of the parcel. On the other hand, the abrupt increase of the $\mathrm{HH}$ and $\mathrm{VV}$ backscattering levels for beam D25 at $\sim \mathrm{BBCH} 14$ is likely due to the row orientation of the parcel with respect to the radar's look direction of this beam.

Note, however, that to exactly quantify the effect of the scene-related disturbing parameters, ground truth information, which is not available in this data set, is needed. 


\section{B. Phenology Estimation}

The mosaic $\mathbf{N}_{\mathbf{C}}$ is specified for each crop type, leading to four mosaics. Each mosaic tile contains regions of interest (ROIs) relevant to the parcels shown in Fig. 1. Individual ROIs are grouped despite if they are geographically separated.

For each crop type, once phenological intervals are identified, the selection of training tiles, as well as the final Wishart classification, is undertaken independently for each parcel. Then, once each pixel of the mosaic is assigned to a given class according to (4), the parcel phenology is decided considering the mode, i.e., the most retrieved value, of the classified pixels. Note that such a decision rule may result in errors since different zones of a parcel may develop at different rates, primarily due to differences in soil and moisture properties across the field. However, this is a convenient way to work according to the ground data, which are provided at parcel level. Finally, results are validated by comparing the retrieved phenological intervals with ground data. A confusion matrix is built for each crop type, updating the diagonal (off-diagonal) elements when phenology is correctly (wrongly) retrieved. It must be underlined that training tiles are not considered in the validation, and the confusion matrices are relevant to the remaining mosaics tiles, referred as testing tiles.

To illustrate the proposed methodology, an example is considered, which refers to the oat parcel. In addition, the effect of sensor configurations, i.e., incidence angle variability across beams, two data sets are considered. The first one consists of all of the beams collected at AOIs $<30^{\circ}$, i.e., beams A23, D25, and A28; the second one includes all the beams. In the case of oat, the smaller set of beams results in a time series of $N=14$ images (see Table III).

The identification step is undertaken, for each parcel, by measuring the pairwise SRWDs (5) between mosaic tiles. The SRWD allows identifying the intervals in an effective way since those tiles characterized by lower distances are representative of similar polarimetric response and hence are merged into unique classes, thus defining the intervals. A threshold $t h r$ is empirically set to identify the $m$ th interval $I_{m}$ as the phenological interval that includes those $N_{m}$ tiles that satisfy two conditions: 1) the distance values between the first tile of $I_{m}$ and the remaining $N_{m}-1$ ones are below thr, and 2) the distance values between the $N_{m}+1$ th tile and the remaining $N-1$ ones are above $t h r$. Note that a maximum number of $M$ phenological intervals, which depend on the sensitivity of the data to the parcel growth stages, can be identified.

As a matter of fact, the first interval $I_{1}$ is determined by evaluating the distance vector $\mathbf{d}^{(1)}$, which contains the distances between the first mosaic tile and the remaining 13 ones, i.e., $\mathbf{d}^{(1)}=\left[d_{\mathrm{SRW}}(1,2), d_{\mathrm{SRW}}(1,3), \ldots, d_{\mathrm{SRW}}(1,14)\right]$ (where, for simplicity, we set $\left.d_{\text {SRW }}\left(\mathbf{C}_{i}, \mathbf{C}_{j}\right)=d_{\text {SRW }}(i, j)\right)$. The vector $\mathbf{d}^{(1)}$, which refers to the observed growing cycle (BBCH 20-99), is plotted, for the three parcels, as a function of the $\mathrm{BBCH}$ scale in Fig. 3(a). Setting an empirical threshold $t h r=0.7$ on these distances, it can be noted that: 1) in the range $20 \leq$ $\mathrm{BBCH} \leq 30$, most of the values $(\sim 93 \%)$ lie below $t h r$, and 2 ) in the range $\mathrm{BBCH}>30$ (hereinafter referred as $\mathrm{BBCH}$ $\left.30^{+}\right)$, most of the values $(\sim 93 \%)$ are above $t h r$. Hence, $I_{1}$ is defined as $20 \leq \mathrm{BBCH} \leq 30$, and it includes the first $N_{1}=4$
$\left(N_{1}=5\right)$ mosaic tiles for parcel $\mathrm{O}_{1}$ (parcels $\mathrm{O}_{2}$ and $\mathrm{O}_{3}$ ). Then, in the next step, the vector $\mathbf{d}^{(2)}$, i.e., the vector that contains the distances between the first tile of the range $\mathrm{BBCH}$ $30^{+}$(i.e., the $N_{1}+1$ th tile) and the remaining ones, is used to identify $I_{2}$, as shown in Fig. 3(b). In this case, setting thr $=$ 0.4 , in the range $30<\mathrm{BBCH} \leq 41\left(\mathrm{BBCH} \mathrm{30} 0^{+}\right), 100(57) \%$ of the $\mathbf{d}^{(2)}$ values lies below (above) $t h r$. Accordingly, $I_{2}=$ $30 \leq \mathrm{BBCH} \leq 41$. Similarly, the third interval is $I_{3}=41 \leq$ $\mathrm{BBCH} \leq 73$ [see Fig. 3(c)], while the fourth and fifth intervals are $I_{4}=73 \leq \mathrm{BBCH} \leq 84$ and $I_{5}=\mathrm{BBCH} 84^{+}$, respectively [see Fig. 3(d)]. Therefore, with respect to oat, $M=5$ phenological intervals are identified by analyzing only beams collected at AOIs $<30^{\circ}$.

The same rationale is applied to barley, wheat, and corn parcels, and the following phenological intervals are identified:

- $M=3$ intervals for barley [see Fig. 3(e)-(f)]: $I_{1}=$ $20 \leq \mathrm{BBCH} \leq 41, \quad I_{2}=41<\mathrm{BBCH} \leq 71$, and $I_{3}=$ $\mathrm{BBCH} 71^{+}$.

- $M=3$ intervals for wheat [see Fig. 3(g)-(h)]: $I_{1}=$ $19 \leq \mathrm{BBCH} \leq 39, \quad I_{2}=39<\mathrm{BBCH} \leq 75$, and $I_{3}=$ $\mathrm{BBCH} 75^{+}$.

- $M=5$ intervals for corn [see Fig. 3(i)-(1)], i.e., $I_{1}=$ $\mathrm{BBCH} \leq 20, \quad I_{2}=20<\mathrm{BBCH} \leq 40, \quad I_{3}=40<\mathrm{BBCH} \leq$ $60, I_{4}=60<\mathrm{BBCH} \leq 75$, and $I_{5}=\mathrm{BBCH} 75^{+}$. In this case, the behavior of $\mathbf{d}^{(1)}$ is not the same for all the parcels. In fact, parcels $\mathrm{C}_{1}, \mathrm{C}_{3}, \mathrm{C}_{5}$, and $\mathrm{C}_{9}$ exhibit increasing distance values up to stage 40 , while the remaining ones exhibit a flat evolution of $\mathbf{d}^{(1)}$, with values mostly below 1 . Such a different behavior is likely due to the row orientation of the parcels (see Table I).

Once phenological intervals are identified, the pairwise SRWD is exploited to select training tiles for each interval. For a given parcel, the training tiles of the $m$ th interval $I_{m}$ are identified by evaluating the distance between each $I_{m}$ tile and the remaining $N-1$ ones. A training tile refers to a subset of tiles that belongs to $I_{m}$ and must satisfy two conditions: 1) the distances between the training tile and this subset must be lower than the distance between tiles belonging to the other phenological intervals and the subset and 2) the size of the subset must be the largest possible. Misclassifications arise when the training tiles of the $I_{m}$ interval result in the lowest distances also for other intervals. Note that, for each phenological interval, a maximum number of training tiles have to be set. In this paper, this number is set to $50 \%$ of the tiles included in each interval. However, in practical cases, the proposed approach needs less than $50 \%$ of the tiles. In fact, the smaller is the number of training tiles, the smaller is the probability of misclassifications with other intervals.

Finally, the complex Wishart classifier is applied to the mosaic of every parcel of each crop type. The output of the classification is shown in Fig. 4, whereas the confusion matrices obtained using the testing tiles are reported, along with the overall accuracy (OA), the producer's accuracy (PA), the user's accuracy (UA), and the kappa coefficient, in Table IV. The best performance is achieved for barley, where OA $~ 86 \%$, PA (UA) is between $75 \%$ and $100 \%$ (80\% and $~ 92 \%)$, and kappa is around 0.8. Regarding oat (wheat), OA is about 70 (61) \%, 


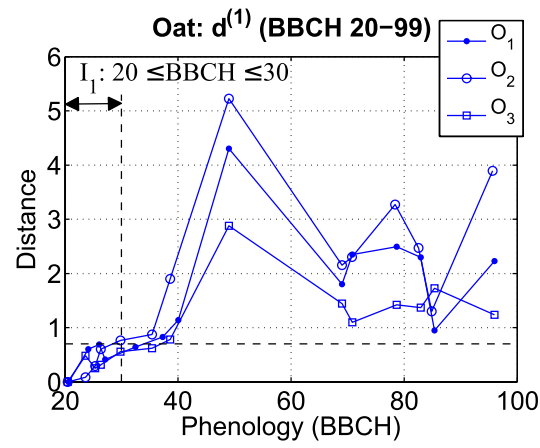

(a)

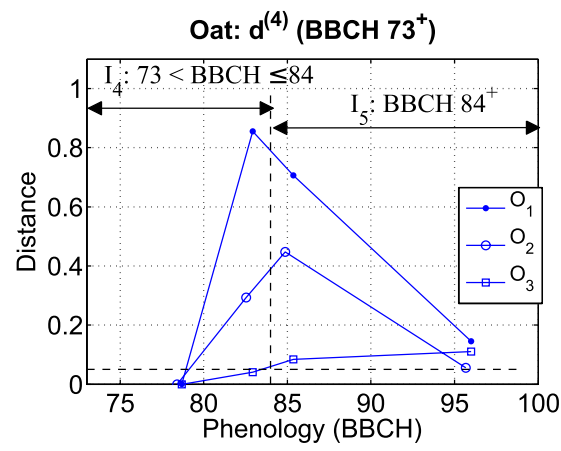

(d)

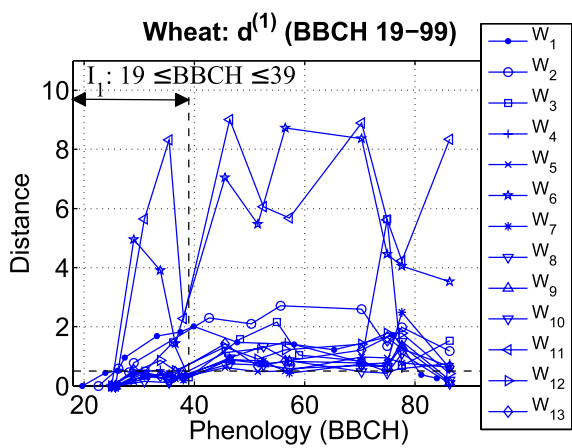

(g)

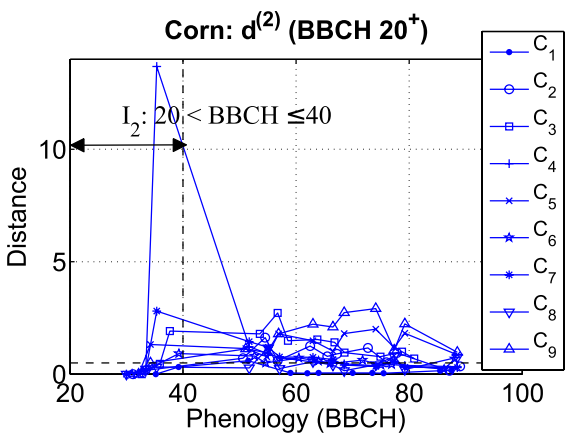

(j)

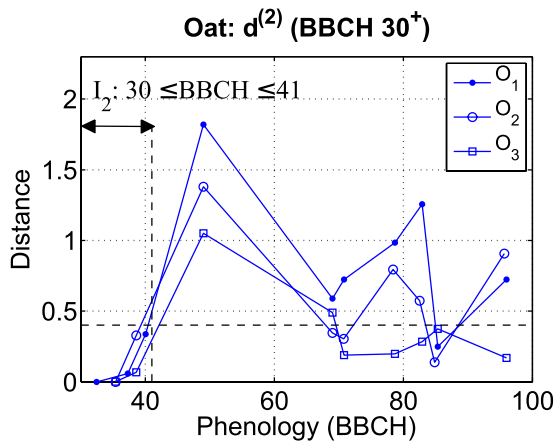

(b)

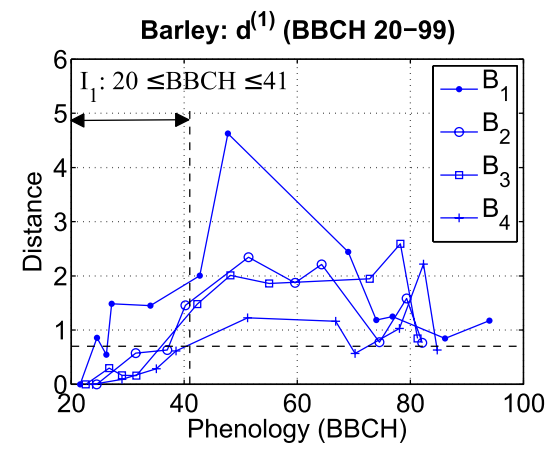

(e)

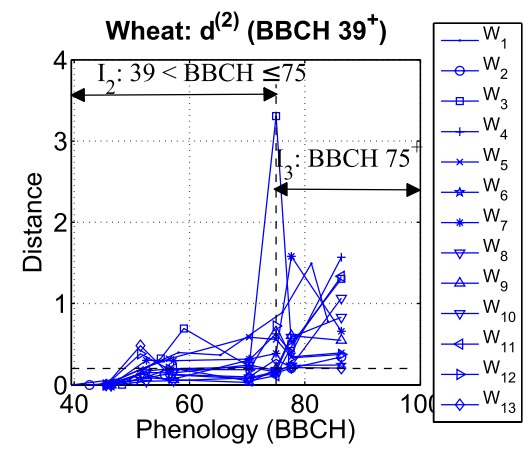

(h)

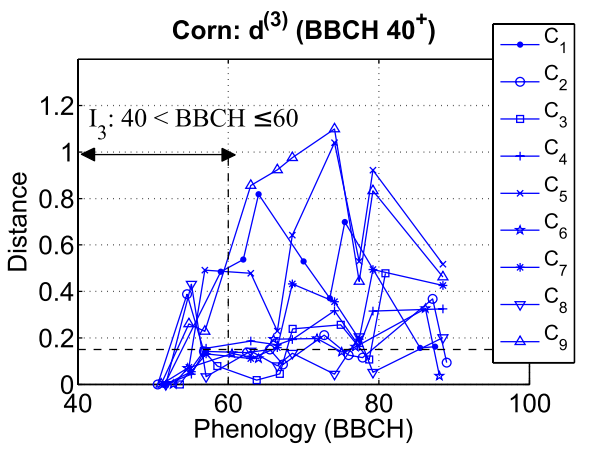

(k)

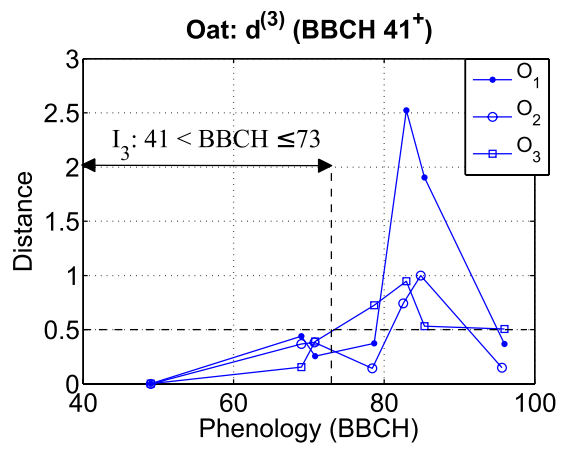

(c)

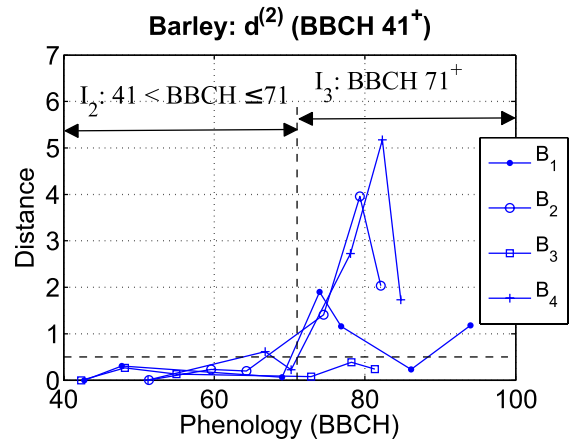

(f)

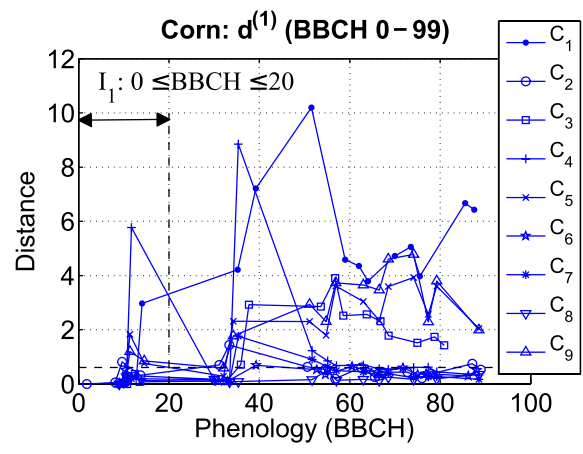

(i)

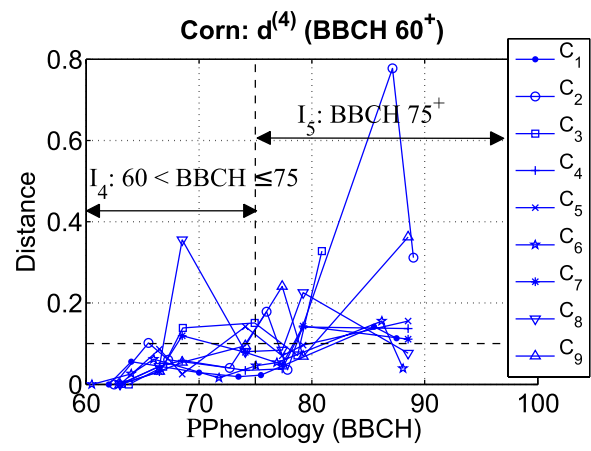

(1)

Fig. 3. Behavior of the elements of the distance vectors $\mathbf{d}^{(1)}, \mathbf{d}^{(2)}, \ldots$, for beams collected at AOIs $<30^{\circ}$. (a)-(d) Oat. (e) and (f) Barley. (g) and (h) Wheat. (i)-(1) Corn. Note that, for each plot, the $m$ th interval $I_{m}$ and the corresponding threshold are annotated.

while for intervals $I_{1}, I_{2}, I_{3}$, and $I_{4}\left(I_{1}\right.$ and $\left.I_{2}\right)$, PA and UA are larger than $40 \%(60 \%)$. The only exception is related to intervals $I_{5}$ (oat) and $I_{3}$ (wheat), where a lack of accuracy is experienced. Kappa is around 0.6 for oat and 0.36 for wheat, respectively. In the case of corn, $\mathrm{OA} \sim 54 \%$, PA ranges from $\sim 21 \%$ to $\sim 90 \%$, while UA varies between $\sim 33 \%$ and $75 \%$. Kappa is 0.42 .
The next experiment consists of applying the proposed methodology on the whole data set. The following phenological intervals are identified:

- $M=6$ intervals for oat: $I_{1}=20 \leq \mathrm{BBCH} \leq 25$, $I_{2}=25 \leq \mathrm{BBCH} \leq 30, \quad I_{3}=30<\mathrm{BBCH} \leq 41, \quad I_{4}=$ $41<\mathrm{BBCH} \leq 73, I_{5}=41<\mathrm{BBCH} \leq 80$, and $I_{6}=$ $\mathrm{BBCH} 80^{+}$. 


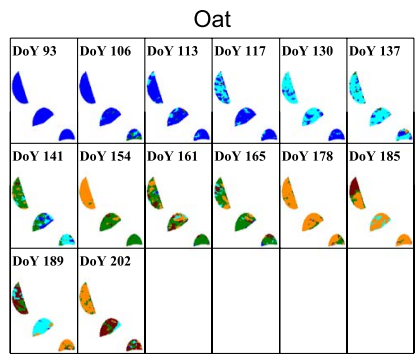

(a)

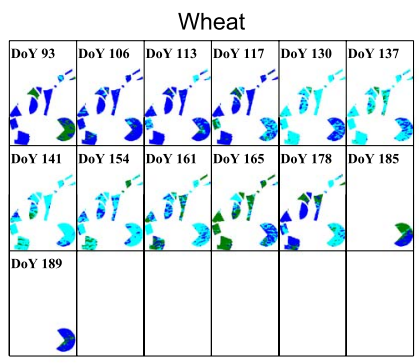

(c)

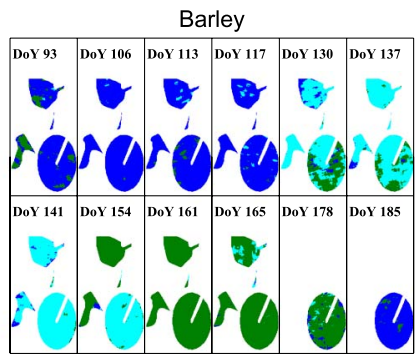

(b)

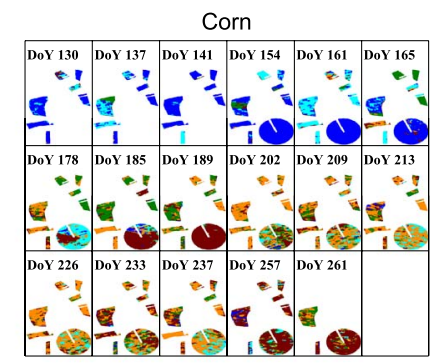

(d)
$I_{1} \square I_{2} \square I_{3} \square I_{4} \square I_{5}$

Fig. 4. Phenology maps obtained by applying the complex Wishart classifier on beams collected at AOIs $<30^{\circ}$ for: (a) oat, (b) barley, (c) wheat, and (d) corn parcels. Phenological intervals refer to the $\mathrm{BBCH}$ scale reported in Table I.

- $M=5$ intervals for barley: $I_{1}=20 \leq \mathrm{BBCH} \leq 30$, $I_{2}=30 \leq \mathrm{BBCH} \leq 41, I_{3}=41<\mathrm{BBCH} \leq 73, I_{4}=$ $73<\mathrm{BBCH} \leq 80$, and $I_{5}=\mathrm{BBCH} 80^{+}$.

- $M=3$ intervals for wheat: $I_{1}=19 \leq \mathrm{BBCH} \leq 39, I_{2}=$ $39<\mathrm{BBCH} \leq 75$, and $I_{3}=\mathrm{BBCH} 75^{+}$.

- $M=4$ intervals for corn: $I_{1}=\mathrm{BBCH} \leq 20, I_{2}=$ $20<\mathrm{BBCH} \leq 40, I_{3}=40<\mathrm{BBCH} \leq 55$, and $I_{5}=$ $\mathrm{BBCH} 55^{+}$.

It can be noted that, with respect to the previous experiment: more intervals are identified for oat and barley; the same three intervals are identified for wheat; the number of intervals reduces to four when corn is considered. Consequently, the exploitation of a denser time series, obtained by combining different beams, does not result in an increased number of intervals for wheat and corn. Such a result is due to the behavior of the distance vectors (not shown here to save space) which, exhibiting a large variability among the parcels, do not allow setting thresholds for the identification of additional intervals. This effect can be explained by considering that, when dealing with wheat and corn, a number of parcels (in some cases located far from each other) larger than the oat and the barley ones are analyzed. As a consequence, including beams collected at different orbits and larger AOIs results in a larger intrafield variability related to the conditions of the parcels (i.e., different growth rates, row orientation, etc.) and the soil (i.e., roughness and moisture). Therefore, a denser time series achieved by combining beams corresponding to different sensor's configurations and scene properties is not always advantageous.

Once training tiles are selected for each parcel, the Wishart classifier is applied to classify the aforementioned phenological intervals. Fig. 5 shows the output of the classifications, whereas the confusion matrices, the specific accuracies, and kappa are listed in Table V. With respect to the previous experiments,
TABLE IV

CONFusion Matrices of THE RETRIEVEd PHENOLOGICAL INTERVALS of THE ANALYZED CROPS For BEAMS COLleCted AT AOIs $<30^{\circ}$

Oat

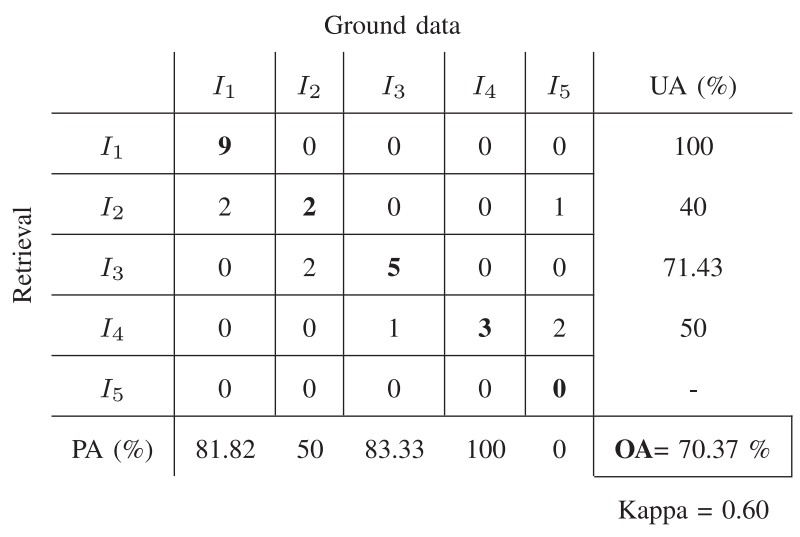

Barley

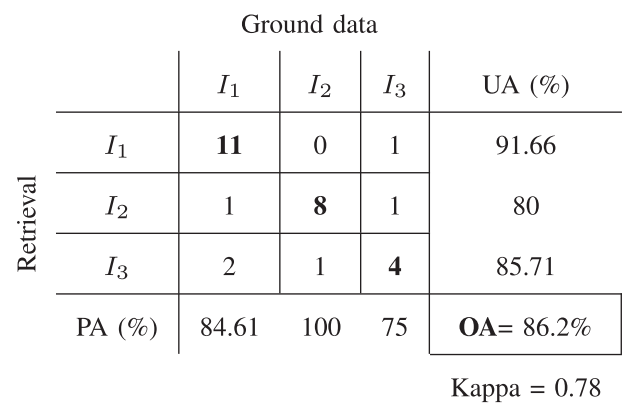

Wheat

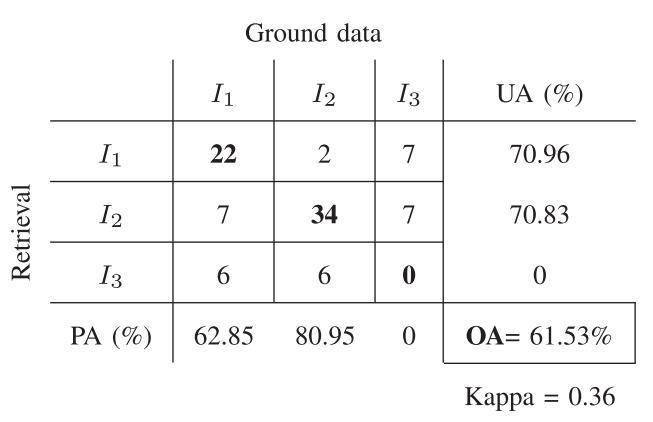

Corn

\begin{tabular}{|c|c|c|c|c|c|c|}
\hline \multicolumn{7}{|c|}{ Ground data } \\
\hline & $I_{1}$ & $I_{2}$ & $I_{3}$ & $I_{4}$ & $I_{5}$ & UA (\%) \\
\hline$I_{1}$ & 12 & 4 & 0 & 0 & 0 & 75 \\
\hline$I_{2}$ & 5 & 3 & 0 & 0 & 1 & 33.33 \\
\hline$I_{3}$ & 0 & 3 & 7 & 1 & 3 & 50 \\
\hline$I_{4}$ & 0 & 3 & 5 & 17 & 7 & 53.1 \\
\hline$I_{5}$ & 1 & 1 & 4 & 1 & 7 & 50 \\
\hline PA (\%) & 66.66 & 21.42 & 43.75 & 89.47 & 38.88 & $\mathbf{O A}=54.11 \%$ \\
\hline & & & & & & Kappa $=0.42$ \\
\hline
\end{tabular}

the overall performances are degraded for oat and barley, while they improve for wheat and corn. OA decreases $\sim 2 \%$ for oat and $\sim 14 \%$ for barley, while it increases $\sim 15 \%(\sim 25 \%)$ for 


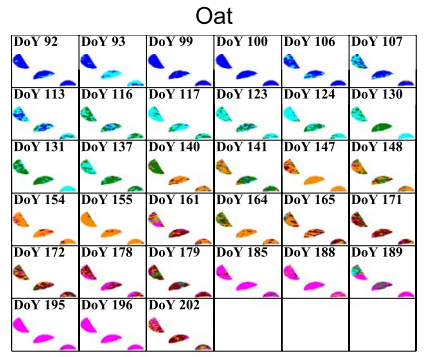

(a)

Wheat

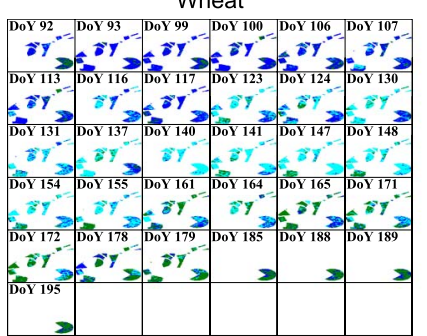

(c)

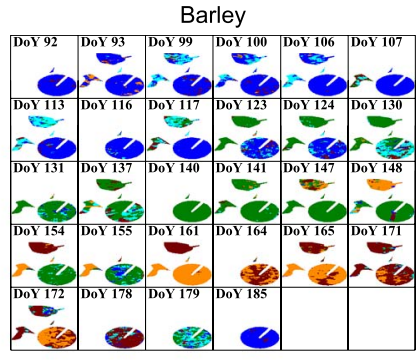

(b)

Corn

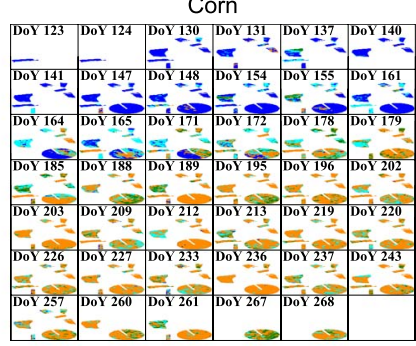

(d)
$I_{1} \square I_{2} \square I_{3} \square I_{4} \square I_{5} \square I_{6}$

Fig. 5. Phenology maps obtained by applying the complex Wishart classifier on the whole set of beams for: (a) oat, (b) barley, (c) wheat, and (d) corn parcels. Phenological intervals refer to the BBCH scale reported in Table I.

TABLE V

Confusion MATRICES OF THE RETRIEVEd PHENOLOGICAL INTERVALS OF THE ANALYZED CROPS FOR THE AVAILABLE BEAMS

Oat

Ground data

\begin{tabular}{|c|c|c|c|c|c|c|c|}
\hline & $I_{1}$ & $I_{2}$ & $I_{3}$ & $I_{4}$ & $I_{5}$ & $I_{6}$ & UA (\%) \\
\hline$I_{1}$ & 9 & 3 & 0 & 0 & 0 & 0 & 100 \\
\hline$I_{2}$ & 3 & 8 & 2 & 0 & 0 & 0 & 61.53 \\
\hline$I_{3}$ & 0 & 3 & 2 & 1 & 0 & 0 & 33.33 \\
\hline$I_{4}$ & 0 & 0 & 3 & 11 & 1 & 0 & 73.33 \\
\hline$I_{5}$ & 0 & 0 & 0 & 2 & 4 & 3 & 44.44 \\
\hline$I_{6}$ & 0 & 0 & 0 & 0 & 2 & 9 & 81.81 \\
\hline PA (\%) & 75 & 72.72 & 28.6 & 78.6 & 57 & 75 & $\mathbf{O A}=68.25 \%$ \\
\hline
\end{tabular}

Barley

\begin{tabular}{|c|c|c|c|c|c|c|}
\hline \multirow{7}{*}{$\begin{array}{c}I_{1} \\
I_{2} \\
I_{3} \\
I_{4} \\
I_{5} \\
\mathrm{PA}(\%)\end{array}$} & $I_{1}$ & $I_{2}$ & $I_{3}$ & $I_{4}$ & $I_{5}$ & UA (\%) \\
\hline & 15 & 1 & 0 & 0 & 1 & 88.23 \\
\hline & 4 & 1 & 0 & 0 & 1 & 16.66 \\
\hline & 0 & 2 & 19 & 0 & 0 & 90.47 \\
\hline & 0 & 0 & 0 & 5 & 2 & 71.43 \\
\hline & 0 & 2 & 0 & 3 & 6 & 54.54 \\
\hline & 78.95 & 16.66 & 100 & 62.5 & 60 & $\mathbf{O A}=74.2 \%$ \\
\hline
\end{tabular}

Wheat

\begin{tabular}{c|c|c|c|c}
\multicolumn{5}{c}{ Ground data } \\
\hline & $I_{1}$ & $I_{2}$ & $I_{3}$ & UA (\%) \\
\hline$I_{1}$ & $\mathbf{6 3}$ & 5 & 8 & 83 \\
\hline$I_{2}$ & 8 & $\mathbf{7 7}$ & 9 & 82 \\
\hdashline$I_{3}$ & 5 & 17 & $\mathbf{2 7}$ & 55 \\
\hline PA (\%) & 83 & 77.77 & 61.36 & OA $=76.25 \%$ \\
\hline \multicolumn{5}{|c}{}
\end{tabular}

Corn

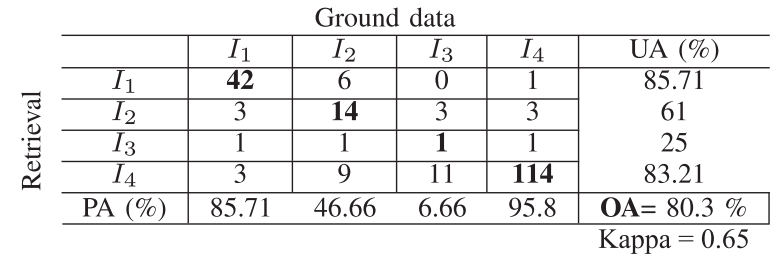

wheat (corn). This is due to the fact that, the larger is the number of intervals identified, the larger is the number of misclassifications to be expected.

\section{CONCLUSION}

In this paper, a new methodology has been proposed to exploit time series of PolSAR images for crop phenology estimation. The methodology is based on the complex Wishart classifier and exploits the whole covariance matrix for phenology retrieval. Consequently, the extraction of further PolSAR features is not necessary, and more importantly, the manual identification of intervals and the definition of rules and thresholds to interpret the evolutions of the features according to phenology are mitigated.

The approach is tested on oat, barley, wheat, and corn crops belonging to the Barrax agricultural area, where a data set that consists of full-pol C-band RADARSAT-2 beams was collected in 2009 with different sensor's configurations (different orbits and AOIs) together with ground truth. Note that short wavelengths, such as C-band ones, are of interest for this application due to their strong interactions with small particles of crops. Experimental results demonstrate that the proposed methodology estimates phenological intervals related to the four crop types with OA between $54 \%$ and $86 \%$, and PA (UA) values ranging from $21 \%$ to $100 \%$ (from $33 \%$ to $100 \%$ ).

The proposed methodology assumes that all changes observed in the radar response along time are due to phenology. As a result, other factors causing variations, either due to the radar system (e.g., incidence angle) and to other scene properties (e.g., soil moisture), affect the performance of this approach. In an ideal case, a time series formed with a single radar beam (e.g., exploiting TerraSAR-X and S1-A/B data, due to their shot revisit time) and auxiliary knowledge of soil conditions would be required to decouple radar variations from its different causes and provide good phenology estimates.

However, in this study, we have analyzed the effect of the incidence angle variability on the estimation performance by applying the proposed methodology first on a subset of beams whose incidence angle varies in a smaller range, and then on the whole data set. Results show that, for a given crop type, exploiting a denser time series, obtained by mixing of different sensor configurations, may hamper the identification of the phenological intervals to be estimated.

Future studies will be devoted at including the information provided by the time variable in this approach in order to conceive a dynamical Wishart classifier for crop phenology estimation.

\section{ACKNOWLEDGMENT}

The authors would like to thank L. Alonso (Universitat de Valencia) and F. de la Cruz (Instituto Tecnico Agronomico Provincial de Albacete) for their helpful explanations about the ground campaign data. All RADARSAT-2 images were provided by ESA in the framework of the AgriSAR 2009 campaign. RADARSAT-2 Data and Products MacDonald, Dettwiler and Associates Ltd. (2009)-All Rights Reserved. RADARSAT is an official trademark of the Canadian Space Agency. 


\section{REFERENCES}

[1] U. Meier, "Growth stages of mono- and dicotyledonous plants," in $B B C H$ Monograph, 2nd ed. Berlin, Germany: Federal Biol. Res. Centre Agriculture Forestry, 2001.

[2] J. C. Zadoks, T. T. Chang, and C. F. Konzak, "A decimal code for the growth stages of cereals," Weed Res., vol. 14, no. 6, pp. 415-421, 1974.

[3] N. Poole, "Disease Management and Crop Canopies," Corp. Barton, Act., Australia, Tech. Rep., 2009.

[4] T. H. Siversten, P. N. Nejedlik, R. Oger, and R. Sigvald, "The Phenology of Crops and the Development of Pests and Diseases: Literature, Research, Models, and Future Operational Integration," Eur. Sci. Found., Strasbourg Cedex, France, COST 711, Tech. Rep., 1999.

[5] J. M. Lopez-Sanchez, J. D. Ballester-Berman, and I. Hajnsek, "First results of rice monitoring practices in Spain by means of time series of TerraSAR-X dual-pol images," IEEE J. Sel. Topics Appl. Earth Observ. Remote Sens., vol. 4, no. 2, pp. 412-422, Jun. 2011.

[6] L. Mascolo, J. M. Lopez-Sanchez, F. Vicente-Guijalba, G. Mazzarella, F. Nunziata, and M. Migliaccio, "On the sensitivity of polarimetric SAR observables to phenological stages of crops in Barrax, Spain: First results at C-band," in Proc. GOLD Remote Sensing, CDROM, Berlin, Germany, 2014.

[7] J. M. Lopez-Sanchez, S. R. Cloude, and J. D. Ballester-Berman, "Rice phenology monitoring by means of SAR polarimetry at X-band," IEEE Trans. Geosci. Remote Sens., vol. 50, no. 7, pp. 2695-2709, Jul. 2012.

[8] J. M. Lopez-Sanchez, F. Vicente-Guijalba, J. D. Ballester-Berman, and S. R. Cloude, "Estimating phenology of agricultural crops from space," presented at the ESA Living Planet Symp., Edinburgh, U.K., Sep. 2013, ESA-SP 722.

[9] J. M. Lopez-Sanchez, F. Vicente-Guijalba, J. D. Ballester-Berman, and S. R. Cloude, "Polarimetric response of rice fields at C-band: Analysis and phenology retrieval," IEEE Trans. Geosci. Remote Sens., vol. 52, no. 5, pp. 2977-2993, May 2014.

[10] Z. Yang, K. Li, L. Liu, Y. Shao, B. Brisco, and W. Li, "Rice growth monitoring using simulated compact polarimetric C band SAR," Radio Sci., vol. 49, no. 12, pp. 1300-1315, 2014.

[11] L. Mascolo, J. M. Lopez-Sanchez, F. Vicente-Guijalba, G. Mazzarella, F. Nunziata, and M. Migliaccio, "Retrieval of phenological stages of onion fields during the first year of growth by means of C-band polarimetric SAR measurements," Int. J. Remote Sens., vol. 36, no. 12, pp. 3077-3096, 2015.

[12] L. Mascolo, J. M. Lopez-Sanchez, F. Vicente-Guijalba, F. Nunziata, M. Migliaccio, and G. Mazzarella, "On the retrieval of phenological stages of agricultural crops by means of C-band polarimetric SAR data in Barrax, Spain," in Proc. POLINSAR, vol. SP-729, CDROM Frascati, Italy, 2015.

[13] O. Yuzugullu, E. Erten, and I. Hajnsek, "Rice growth monitoring by means of X-band co-polar SAR: Feature clustering and BBCH scale," IEEE Geosci. Remote Sens. Lett., vol. 12, no. 6, pp. 1218-1222, Jun. 2015.

[14] F. Vicente-Guijalba, T. Martinez-Marin, and J. M. Lopez-Sanchez, "Crop phenology estimation using a multitemporal model and a Kalman filtering strategy," IEEE Geosci. Remote Sens. Lett., vol. 11, no. 6, pp. 1081-1085, Jun. 2014.

[15] F. Vicente-Guijalba, T. Martinez-Marin, and J. M. Lopez-Sanchez, "Dynamical approach for real-time monitoring of agricultural crops," IEEE Trans. Geosci. Remote Sens., vol. 53, no. 6, pp. 3278-3293, Jun. 2015.

[16] C. De Bernardis, F. Vicente-Guijalba, T. Martinez-Marin, and J. M. Lopez-Sanchez, "Estimation of key dates and stages in rice crops using dual-polarization SAR time series and a particle filtering approach," IEEE J. Sel. Topics Appl. Earth Observ. Remote Sens., vol. 8, no. 3, pp. 1088-1018, Mar. 2015.

[17] J. M. Lopez-Sanchez, F. Vicente-Guijalba, J. D. Ballester-Berman, and S. R. Cloude, "Retrieving rice phenology with X-band co-polar data: A multi-incidence multi-year experiment," in Proc. IEEE IGARSS, Milano, Italy, Jul. 2015, pp. 3977-3980.

[18] C. Kucuk, G. T. Kaya, and E. Erten, "Co-polar SAR data classification as a tool for real time paddy-rice monitoring," in Proc. IEEE IGARSS, Milano, Italy, Jul. 2015, pp. 4141-4144.

[19] C. Kucuk, G. Taskin, and E. Erten, "Paddy-rice phenology classification based on machine-learning methods using multitemporal co-polar X-band SAR images," IEEE J. Sel. Topics Appl. Earth Observ. Remote Sens., vol. 9, no. 6, pp. 2509-2519, Jun. 2016, doi: 10.1109/JSTARS.2016.2547843.

[20] C. De Bernardis, F. Vicente-Guijalba, T. Martinez-Marin, and J. M. Lopez-Sanchez, "Contribution to real-time estimation of crop phenological states in a dynamical framework based on NDVI time series: Data fusion with SAR and temperature," IEEE J. Sel. Topics Appl. Earth Observ. Remote Sens., doi: 10.1109/JSTARS.2016.2539498.
[21] J. S. Lee, M. R. Grunes, and R. Kwok, "Classification of multi-look polarimetric SAR imagery based on complex Wishart distribution," Int. J. Remote Sens., vol. 15, no. 11, pp. 2299-2311, 1994.

[22] M. S. Moran, L. Alonso, J. F. Moreno, M. P. Cendrero Mateo, D. F. dela Cruz, and A. Montoro, "A RADARSAT-2 quad-polarized time series for monitoring crop and soil conditions in Barrax, Spain," IEEE Trans. Geosci. Remote Sens., vol. 50, no. 4, pp. 1057-1070, Apr. 2012.

[23] J. Lee and E. Pottier, Polarimetric Radar Imaging: From Basics to Applications. Boca Raton, FL, USA: CRC Press, 2009.

[24] N. R. Goodman, "Statistical analysis based on a certain multivariate complex Gaussian distribution (an introduction)," Ann. Math. Statist., vol. 34, pp. 152-177, 1963.

[25] J. S. Lee, M. R. Grunes, E. Pottier, and L. Ferro-Famil, "Unsupervised terrain classification preserving polarimetric scattering characteristics," IEEE Trans. Geosci. Remote Sens., vol. 42, no. 4, pp. 722-731, Apr. 2004

[26] S. N. Anfinsen, R. Jenssen, and T. Eltoft, "Spectral clustering of polarimetric SAR data with Wishart-derived distance measures," in Proc. POLINSAR, Frascati, Italy, 2007, pp. 1-8.

[27] M. C. Gonzlez-Sanpedro, T. Le Toan, J. F. Moreno, L. Kergoat, and E. Rubio, "Seasonal variations of leaf area index of agricultural fields retrieved from Landsat data," Remote Sens. Environ., vol. 112, no. 3, pp. 810-824, 2008.

[28] S. W. Ritchie, J. J. Hanway, and G. O. Benson, "How a Corn Plant Develops: Special Report No 48," Coop. Ext. Serv., Iowa State Univ., Ames, IA, USA, Tech. Rep., 1986.

[29] Y. Ban and P. J. Howarth, "Orbital effects on ERS-1 SAR temporal backscatter profiles of agricultural crops," Int. J. Remote Sens., vol. 19, no. 17, pp. 3465-3470, 1998.

[30] P. Saich and M. Borgeaud, "Interpreting ERS SAR signatures of agricultural crops in Flevoland, 1993-1996," IEEE Trans. Geosci. Remote Sens., vol. 38, no. 2, pp. 651-657, Mar. 1998.

[31] F. Mattia et al., "Multitemporal C-band radar measurements on wheat fields," IEEE Trans. Geosci. Remote Sens., vol. 41, no. 7, pp. 1551-1560, Jul. 2003.

[32] G. Picard, T. Le Toan, F. Mattia, and T. Le Toan, "Understanding C-band radar backscatter from wheat canopy using a multiple-scattering coherent model," IEEE Trans. Geosci. Remote Sens., vol. 41, no. 7, pp. 1583-1591, Jul. 2003.

[33] S. C. M. Brown, S. Quegan, K. Morrison, J. C. Bennett, and G. CookMartin, "High resolution measurements of scattering in wheat canopies-Implications for crop parameter retrieval," IEEE Trans. Geosci. Remote Sens., vol. 41, no. 7, pp. 1583-1591, Jul. 2003.

[34] G. Satalino, A. Balenzano, F. Mattia, and M. W. J. Davidson, "C-band SAR data for mapping crops dominated by surface or volume scattering," IEEE Geosci. Remote Sens. Lett., vol. 11, no. 2, pp. 384-388, Feb. 2014.

[35] H. McNairn and B. Brisco, "The application of C-band polarimetric SAR for agriculture: A review," Can. J. Remote Sens., vol. 30, no. 3, pp. 525-542, 2004.

[36] H. McNairn, K. Hochheim, and N. Rabe, "Applying polarimetric radar imagery for mapping the productivity of wheat crops," Can. J. Remote Sens., vol. 30, no. 3, pp. 517-524, 2004.

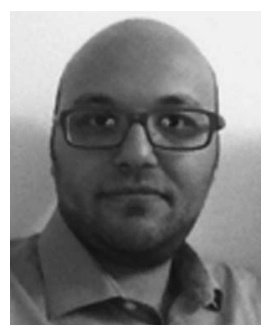

Lucio Mascolo (S'12-M'16) was born in Italy in 1983. He received the B.Sc. and M.Sc. degrees (summa cum laude) in telecommunications engineering from the Università degli Studi di Napoli "Parthenope," Naples, Italy, in 2007 and 2011, respectively, and the Ph.D. degree in electronic and information engineering (curriculum electromagnetic fields) from the Università degli Studi di Cagliari, Cagliari, Italy, in 2015.

Since 2015, he has been with the Remote Sensing Group, Università degli Studi di Napoli "Parthenope." His research activities mainly deal with electromagnetic modeling, radar polarimetry, polarimetric SAR data analysis, and remote sensing for land applications (monitoring of vegetated areas and agricultural crops). 


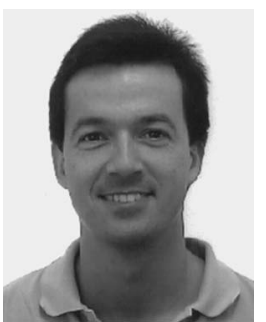

Juan M. Lopez-Sanchez (S'94-M'00-SM'05) was born in Alicante, Spain, in 1972. He received the Ingeniero (M.S.) and Doctor Ingeniero (Ph.D.) degrees in telecommunication engineering from the Technical University of Valencia (UPV), Valencia, Spain, in 1996 and 2000, respectively.

From 1998 to 1999, he was a Predoctoral Grantholder with the Space Applications Institute, Joint Research Centre, European Commission, Ispra, Italy. Since 2000, he has been the Lead of the Signals, Systems and Telecommunication Group, University of Alicante, Alicante, where he has been a Full Professor since November 2011. $\mathrm{He}$ is the coauthor of more than 55 papers in refereed journals and more than 100 papers and presentations in international conferences and symposia. His main research interests include microwave remote sensing for inversion of biophysical parameters, polarimetric and interferometric techniques, SAR imaging algorithms, and applications of radar remote sensing in agriculture and geophysics.

Dr. Lopez-Sanchez received the Indra Award for the best Ph.D. thesis about radar in Spain in 2001. From 2006 to 2012, he was the Chair of the Spanish Chapter of the IEEE Geoscience and Remote Sensing Society.

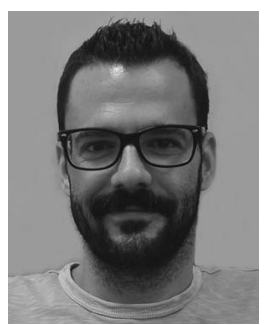

Fernando Vicente-Guijalba (S'12) was born in Elche, Alicante, Spain, in 1981. He received the Ingeniero Tecnico degree in telecommunication engineering, the Ingeniero degree in sound and image in telecommunication engineering, and the Ph.D. degree in computer science from the University of Alicante, Alicante, in 2006, 2011, and 2016 respectively.

Since 2011, he has been collaborating with the Signals, Systems and Telecommunications (SST) Group, University of Alicante. His current research interests include dynamical system analysis with applications in polarimetric and interferometric SAR methods.

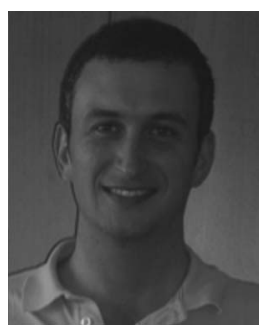

Ferdinando Nunziata (S'03-M'12-SM'14) was born in Italy in 1982. He received the B.Sc. and M.Sc. degrees (summa cum laude) in telecommunications engineering and the Ph.D. degree (curriculum electromagnetic fields) from the Università degli Studi di Napoli "Parthenope," Naples, Italy, in 2003, 2005, and 2008, respectively.

Since 2010, he has been an Assistant Professor of electromagnetic fields with the Università degli Studi di Napoli "Parthenope." Since 2013, he has been a Guest Professor with Shanghai Ocean University (SHOU), Shanghai, China. He is the author/coauthor of more than 50 peerreviewed journal papers. His main research interests deal with applied electromagnetics, including electromagnetic modeling, single- and multipolarization sea surface scattering, radar polarimetry, synthetic aperture radar sea oil slick and metallic target monitoring, spatial resolution enhancement techniques, and Global Navigation Satellite System-Reflectometry.

Dr. Nunziata was the recipient of the 2003 IEEE GRS South Italy Chapter Best Remote Sensing Thesis Award, the 2009 Sebetia-Ter International Award for his research activities in remote sensing, and the 2012 Latmiral Prize, provided by the Italian Society of Electromagnetics (SIEm). He was/is in the Organizing Committee of the 2008, 2010, 2012, and 2014 IEEE Graduate of Last Decade (GOLD) Remote Sensing Conferences at the European Space Agency, Frascati, Italy, at the Italian Naval Academy, Livorno, Italy, at the National Research Council, Rome, Italy, and in Berlin, Germany, respectively. He is a Young Professional (formerly GOLD) representative to the Geoscience and Remote Sensing Society Administrative Committee and to the IEEE Italy Section.

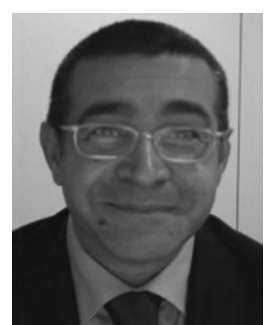

Maurizio Migliaccio (M'91-SM'00) was born in Naples, Italy, in 1962. He received the Laurea degree (with honors) in electronic engineering from the Università degli Studi di Napoli “Federico II,"Naples, in 1987.

He has been a Full Professor of electromagnetics with the Università degli Studi di Napoli "Parthenope," Naples, since 2005, where he is the Chairman of the telecommunication courses, and an Affiliated Full Professor with Nova Southeastern University, Fort Lauderdale, FL, USA, since 2013. $\mathrm{He}$ has been teaching microwave remote sensing since 1994. He was a member of the Italian Space Agency Scientific Committee. He was a Visiting Scientist with Deutsche Forschungsanstalt fur Luft und Raumfahrt (DLR), Oberpfaffenhofen, Germany. He lectured in Italy, U.S., Germany, Spain, Czech Republic, and China. He is an Italian delegate at UE COST SMOS Mode Action. He published more than 150 peer-reviewed journal papers on remote sensing and applied electromagnetics. His current scientific interests cover SAR oil slick and man-made target monitoring, remote sensing for marine and coastal applications, polarimetry, inverse problem for resolution enhancement, and reverberating chambers.

Prof. Migliaccio has been an ASI delegate at e-geos Administrative Committee. He is a member of the ASI CSG panel. He was a member of the ESA PB-EO. He was a promoter and an organizer of the IEEE GOLD Remote Sensing Conferences and the Chairman of the IEEE GRS South Italy Chapter $\mathrm{He}$ is an Associate Editor of the International Journal of Remote Sensing and IEEE JOURNAL OF SELECTED TOPICS ON APPLIED EARTH OBSERVATIONS AND REMOTE SENSING on the special issue on COSMO-SkyMed.

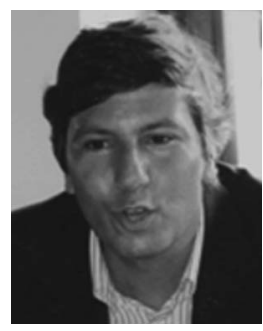

Giuseppe Mazzarella (S'82-M'90-SM'99) received the B.S. degree (summa cum laude) in electronic engineering and the Ph.D. degree in electronic engineering and computer science from the Università degli Studi di Napoli “Federico II,” Naples, Italy, in 1984 and 1989, respectively.

In 1990, he became an Assistant Professor with the Dipartimento di Ingegneria Elettronica, Universit "Federico II". Since 1992, he has been with the Dipartimento di Ingegneria Elettrica ed Elettronica, Università degli Studi di Cagliari, Cagliari, Italy, first as an Associate Professor and then as a Full Professor since 2000, teaching courses in electromagnetics, microwave, antennas, and remote sensing. He is the author (or coauthor) of about 50 papers in international journals and is a reviewer for many EM journals. His research activity has focused mainly on the following: efficient synthesis of large arrays of slots, power synthesis of array factor, microwave holography techniques for the diagnostic of large reflector antennas, and use of evolutionary programming for inverse problem solving. 